\title{
Molecularly targeted therapy and immunotherapy for hormone receptor-positive/human epidermal growth factor receptor 2-negative advanced breast cancer (Review)
}

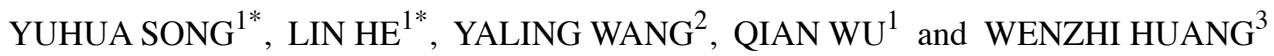 \\ ${ }^{1}$ Breast Disease Center, The Affiliated Hospital of Qingdao University; ${ }^{2}$ Department of Oncology, The Second Affiliated \\ Hospital of Medical College of Qingdao University, Qingdao, Shandong 266000; ${ }^{3}$ Department of Oncology, \\ The PLA Navy Anqing Hospital, Anqing, Anhui 246000, P.R. China
}

Received October 15, 2019; Accepted April 1, 2020

DOI: $10.3892 /$ or.2020.7589

\begin{abstract}
The advent of targeted therapy for hormone receptor-positive/human epidermal growth factor receptor 2-negative advanced breast cancer $\left(\mathrm{HR}^{+} / \mathrm{HER} 2^{-} \mathrm{aBC}\right)$ provides a novel therapeutic approach other than endocrine therapy. One targeted signaling pathway and three immune-checkpoints have been demonstrated to be in association with tumor proliferation and growth in $\mathrm{HR}^{+} / \mathrm{HER} 2^{-}$aBC. A number of phosphoinositide 3-kinase/AKT/mammalian target of rapamycin signaling pathway inhibitors demonstrate clinical activity against this tumor subtype. The CDK4/6 inhibitors as a single agent or in combination with endocrine therapy have produced promising tumor response with acceptable toxicity in patients with $\mathrm{HR}^{+} / \mathrm{HER} 2^{-}$aBC. Programmed death 1/programmed death ligand 1 (PD1/PD-L1) and cytotoxic T lymphocyte antigen-4 inhibitors can also produce an antitumor
\end{abstract}

Correspondence to: Dr Yuhua Song, Breast Disease Center, The Affiliated Hospital of Qingdao University, 59 Haier Road, Laoshan, Qingdao, Shandong 266000, P.R. China

E-mail: qdsongyh@126.com

Contributed equally

Abbreviations: HR, hormone receptor; Tregs, regulatory $\mathrm{T}$ cells; PFS, progression-free survival; $\mathrm{HR}^{+} / \mathrm{HER} 2 \mathrm{aBC}$, HR-positive/human epidermal growth factor receptor 2-negative advanced breast cancer; TNBC, triple-negative breast cancer; TILs, tumor-infiltrating lymphocytes; PD1/PD-L1, programmed death 1/programmed death ligand 1; CTLA-4, cytotoxic T lymphocyte antigen-4; PI3K, phosphoinositide 3-kinase; AKT, protein kinase B; mTOR, mammalian target of rapamycin; PIK3CA, PI3K, catalytic, a polypeptide; AEs, adverse events; MTD, maximum tolerated dose; ORR, overall response rate; $\mathrm{CBR}$, clinical benefit rate; ER, estrogen receptor; CDK4/6, cyclin-dependent kinase 4 and 6; $\mathrm{Rb}$, retinoblastoma; TCR, T-cell receptor

Key words: targeted therapy, immunotherapy, hormone receptor, human epidermal growth factor receptor 2 , breast cancer immune response, which provides a proof-of-principle for the initial utilization of immunotherapy in breast cancer. The aim of the present review was to discuss the mechanisms of action, clinical efficacy and safety profiles of all the targeted biological therapies and immunotherapies that have been approved or are currently under evaluation for $\mathrm{HR}^{+} / \mathrm{HER} 2^{-} \mathrm{aBC}$.

\section{Contents}

1. Introduction

2. PI3K/AKT $/ m$ TOR signaling pathway inhibitors

3. Cyclin-dependent kinase 4 and 6 (CDK4/6) inhibitors

4. Anti-PD1/PD-L1

5. Anti-CTLA-4

6. Conclusions

\section{Introduction}

Of the 1.5 million new-onset breast cancer cases diagnosed annually worldwide, a large subset are hormone receptor (HR)-positive breast cancers [estrogen receptor (ER)-positive, progesterone receptor-positive, or both, with normal human epidermal growth factor receptor 2 (HER2) expression], accounting for $\sim 60-65 \%$ (1). Patients with this disease $(>70 \%)$ are significantly more commonly diagnosed at an advanced stage compared with those with other subtypes of breast cancer (2). Over several decades, the mainstay in the treatment of women with advanced $\mathrm{HR}$-positive $\left(\mathrm{HR}^{+}\right)$breast cancer has been hormone therapy, which may benefit patients initially, but eventually leads to drug resistance and disease progression. Endocrine therapy-refractory patients are not considered as suitable candidates for a combination of endocrine therapy and chemotherapy, as this combination may accentuate the expression of naïve regulatory $\mathrm{T}$ cells (Tregs) that are associated with disease progression or death (3). Clinical studies have demonstrated that everolimus [a mammalian target of rapamycin (mTOR) inhibitor] or tucidinostat (a histone deacetylase inhibitor) in combination with exemestane (an aromatase inhibitor) achieved significant improvement of the 
progression-free survival (PFS) of patients with $\mathrm{HR}^{+} / \mathrm{HER} 2$ advanced breast cancer ( $\mathrm{aBC}$ ), who had become resistant to endocrine therapy $(4,5)$. These findings heightened the interest in the application of targeted therapy for such patients.

Immunotherapy has also shown promising clinical efficacy in breast cancer, specifically in triple-negative breast cancer (TNBC), due to its immune-rich characteristics (6), and is currently the fifth treatment strategy for breast carcinoma after surgery, chemotherapy, radiotherapy and molecularly targeted therapy. By contrast, $\mathrm{HR}^{+}$breast tumor is an immunologically cold cancer. Metastatic disease due to the escape from immune surveillance at the primary tumor site contributes to the lower immunogenicity of the metastases compared with the primary tumor. Moreover, previous chemotherapy depletes immune-active tumors, giving rise to the development of immunologically cold tumors in aBC. All these underpinnings are associated with a weakened response of $\mathrm{HR}^{+} / \mathrm{HER} 2-$ aBC to immunotherapy. However, in the context of high numbers of tumor-infiltrating lymphocytes (TILs) and immune-related gene expression signatures, these patients may benefit from systematic adjuvant therapy (7). Several clinical trials confirmed the antitumor activities of inhibiting immune-checkpoints, such as programmed death 1/programmed death ligand 1 (PD1/PD-L1) and cytotoxic T lymphocyte antigen-4 (CTLA-4) in breast cancer (8-11). The aim of the present study was to evaluate the mechanisms of action and the therapeutic efficacy and tolerability of targeted therapy and immunotherapy for $\mathrm{HR}^{+} / \mathrm{HER} 2^{-} \mathrm{aBC}$.

\section{PI3K/AKT/mTOR signaling pathway inhibitors}

The phosphoinositide 3-kinase/protein kinase B (PI3K/AKT) signaling pathway is crucial for cell survival and proliferation via multiple downstream effectors, including mammalian target of rapamycin (mTOR) (12). In $\mathrm{HR}^{+}$breast cancer, mutations of the activated PI3K, catalytic, a polypeptide (PIK3CA) occur frequently, increase the AKT level and may give rise to the insensitivity to antitumor therapy $(12,13)$. Several cytotoxic agents and mTOR inhibitors are available that can reduce the size and even eliminate tumors, although activation of ATK signaling reduces their therapeutic effectiveness (14-17). Estrogen-induced cell proliferation in breast tumors depends on mTOR signaling (18), and mTOR inhibition can downregulate the expression of ER. Therefore, inhibition of mTOR signaling may effectively reduce cell proliferation in $\mathrm{HR}^{+}$ breast tumors, even when they have been proven to be resistant to hormone therapy (19). In breast cancer xenograft models, a PI3K inhibitor can abolish the activation of ATK signaling induced by mTOR inhibition. Under hypoxic conditions, inhibition of the PI3K/ATK/mTOR signaling pathway can reduce the expression of hypoxia-inducible factor 1a and the synthesis of vascular endothelial growth factor, both of which promote angiogenesis in tumors (Fig. 1) (16). These mechanisms constitute the conceptual framework for investigating the antitumor activity of PI3K inhibitors, ATK inhibitors and mTOR inhibitors for the treatment of patients with $\mathrm{HR}^{+}$breast cancer.

PI3K inhibitors. Buparlisib (BKM120), an oral reversible PI3K inhibitor, manifests antitumor efficacy as monotherapy and in combination with endocrine therapy for the treat- ment of patients with $\mathrm{HR}^{+}$breast cancer independently of the presence of PIK3CA mutations $(20,21)$. Two phase III randomized controlled trials (RCTs), BELLE-2 (22) and BELLE-3 (23), demonstrated that buparlisib-fulvestrant significantly prolonged the median $\mathrm{PFS}$ of $\mathrm{HR}^{+} / \mathrm{HER} 2$ endocrine treatment-refractory aBC postmenopausal patients compared with fulvestrant (Table I). However, no additional studies were launched to explore the clinical benefit and safety in this setting, due to the serious toxicity of the combined treatment; the most common grade 3-4 adverse events (AEs) were increased alanine aminotransferase and aspartate aminotransferase levels, and hyperglycemia (Table I). As a result, the clinical application of buparlisib has been limited and several other trials have been initiated to test a-specific PI3K inhibitors in patients.

Alpelisib (BYL719) is an orally selective, bioavailable, $\alpha$-specific PI3K small-molecule inhibitor, which acts synergistically with hormone therapy against $\mathrm{HR}^{+}$PIK3CA-mutant breast cancer (24). The maximum tolerated dose (MTD) of alpelisib combined with letrozole or fulvestrant is different, 300 and $400 \mathrm{mg}$ daily, respectively $(24,25)$. Both drug combinations have manageable safety profiles, with reversible toxicity. Additionally, these combinations are associated with greater clinical benefits in PIK3CA-mutated $\mathrm{HR}^{+} / \mathrm{HER} 2^{-}$aBC compared with PIK3CA-wild-type tumors. However, FGFRI amplification is an adverse factor in the antitumor activity of alpelisib in $\mathrm{HR}^{+} / P I K 3 C A$-mutant breast cancer (24), suggesting that alpelisib should not be administered to patients with coexisting genomic alterations. The NEO-ORB phase II clinical study (26) indicated that alpelisib-letrozole did not improve the response of postmenopausal women with early $\mathrm{HR}^{+} / \mathrm{HER} 2^{-}$breast cancer compared with placebo-letrozole in the neoadjuvant setting, regardless of the patients' PIK3CA mutation status (Table I). By contrast, alpelisib-fulvestrant compared with placebo-fulvestrant significantly prolonged the median PFS, increased the overall response rate (ORR; complete or partial response) to $\geq 24$ weeks and increased the clinical benefit rate (ORR + stable disease) to $\geq 24$ weeks (CBR) in postmenopausal patients with endocrine-refractory $\mathrm{HR}^{+} / \mathrm{HER} 2^{-}$PIK3CA-mutant aBC; however, no difference was observed in patients with PIK3CA-wild-type tumors (SOLAR-1 trial) (27). The most frequent grade 3-4 treatment-associated AEs in the alpelisib group were hyperglycemia, rash and maculopapular rash (Table I). These findings collectively suggest that alpelisib in combination with endocrine therapy should only be used for the treatment of patients with $\mathrm{HR}^{+} / \mathrm{HER} 2$, PIK3CA-mutant aBC.

AKT inhibitors. MK-2206, an orally selective and potent allosteric AKT inhibitor (28), induces apoptosis in parental $\mathrm{ER}^{+}$ breast cancer cell lines, but not in those subjected to long-term estrogen deprivation. MK-2206 in combination with endocrine agents for the treatment of $\mathrm{HR}^{+} / \mathrm{HER} 2^{-}$aBC has achieved a tumor response that is not dependent on the PIK3CA-mutant status $(29,30)$. Unexpectedly, this combination therapy does not enhance the antitumor efficacy in early-stage $\mathrm{HR}^{+} / \mathrm{HER} 2$ breast cancer compared with endocrine therapy alone (31). Overall, further phase II/III clinical trials are required to investigate the clinical activity and safety profile of MK-2206 in $\mathrm{HR}^{+} / \mathrm{HER} 2^{-} \mathrm{aBC}$. 


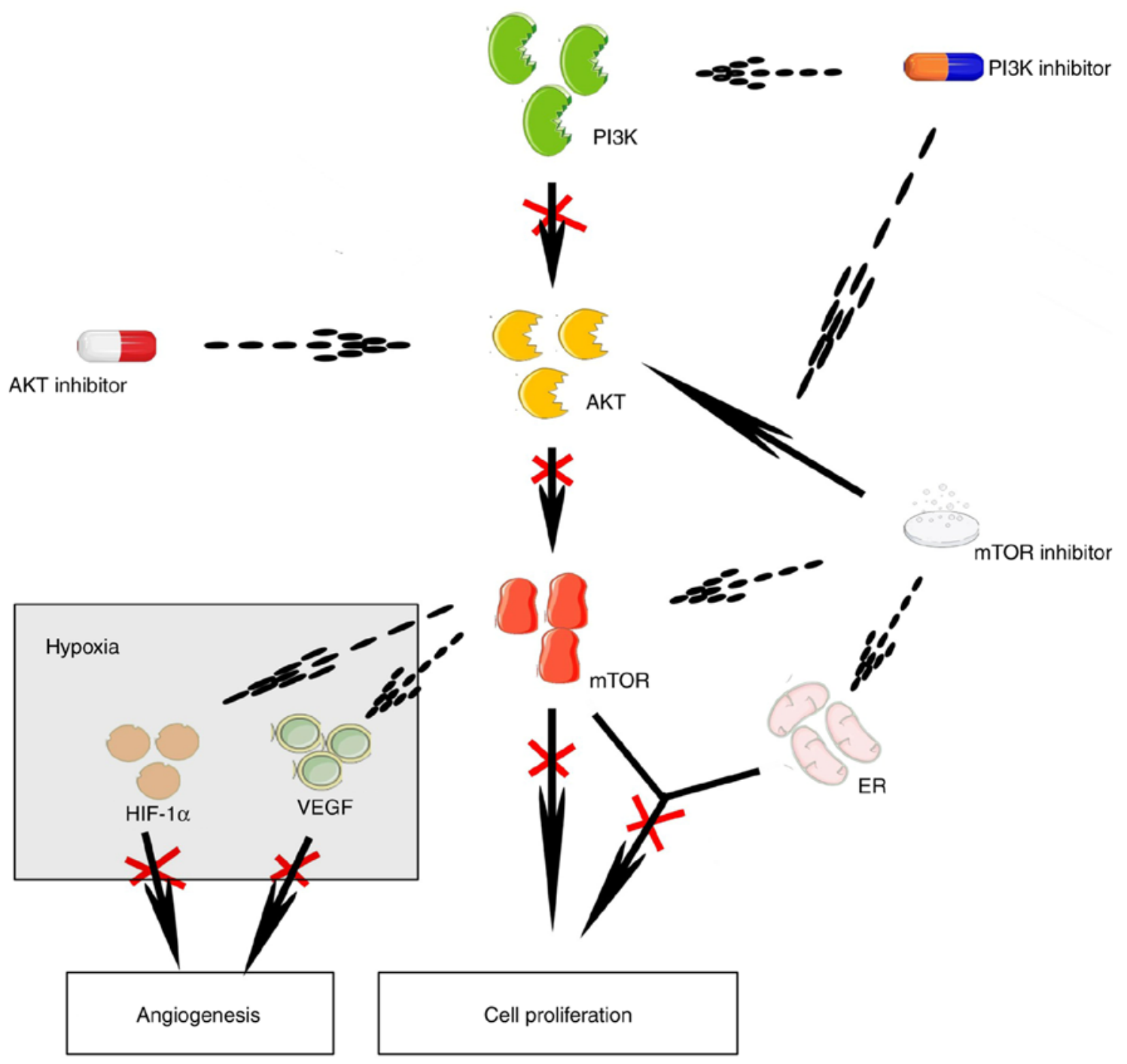

Figure 1. Mechanisms underlying the antitumor effect of CDK4/6 inhibitors. Solid arrow, promoting effect; dashed arrow, inhibiting effect; red cross solid arrow, weakening effect caused by previous step. Gray box represents hypoxic environment. PI3K, phosphoinositide 3-kinase; AKT, protein kinase B; mTOR, mammalian target of rapamycin; ER, estrogen receptor; VEGF, vascular endothelial growth factor; HIF-1 $\alpha$, hypoxia-inducible factor-1 $\alpha$.

Capivasertib (AZD5363) is another orally selective and potent AKT inhibitor, the sensitivity of cancer to which is increased by the presence of the PIK3CA mutation (32). Estrogen blockade may be crucial for its antitumor activity, as capivasertib does not improve the median PFS of patients with $\mathrm{HR}^{+} / \mathrm{HER} 2^{-}$aBC receiving paclitaxel without endocrine agents, even in the PIK3CA-mutant subpopulation (BEECH trial; Table I) (33). Capivasertib exerts a synergistic effect with fulvestrant in delaying tumor progression in xenograft models of $\mathrm{ER}^{+}$breast cancer (34); further investigation of the clinical activity and safety of capivasertib-fulvestrant in patients with $\mathrm{HR}^{+} / \mathrm{HER} 2^{-}{ }^{-} \mathrm{BC}$ is ongoing (NCT01992952).

mTOR inhibitors. Everolimus (Afinitor), an orally selective and potent allosteric mTOR inhibitor (35), acts synergistically with letrozole to suppress cell proliferation and trigger apoptosis in $\mathrm{ER}^{+}$breast cancer cells (18). In the neoadjuvant setting, everolimus can significantly increase the ORR of patients with early $\mathrm{HR}^{+} / \mathrm{HER} 2^{-}$breast cancer who receive letrozole monotherapy (36). Numerous phase II and III clinical trials, including the 4EVER trial (37), GINECO study (38), BOLERO-2 trial (4),
BOLERO-4 trial (39) and BOLERO-6 trial (40), have explored the antitumor efficacy and safety profile of everolimus combined with aromatase inhibitors in $\mathrm{HR}^{+} / \mathrm{HER} 2^{-}$aBC (Table I). Taken together, the combination significantly prolongs the median PFS of postmenopausal patients with $\mathrm{HR}^{+} / \mathrm{HER} 2^{-}$aBC compared with aromatase inhibitors or everolimus alone, with acceptable toxicity. This combined strategy appears to be a good first- and second-line treatment option for patients with $\mathrm{HR}^{+} / \mathrm{HER} 2$ $\mathrm{aBC}$, as it is more effective and less toxic compared with most chemotherapy protocols (41), particularly as first-line therapy, as its median PFS is longer compared with that of second-line therapy (39).

\section{Cyclin-dependent kinase 4 and 6 (CDK4/6) inhibitors}

The interaction of CDK4/6 with D-type cyclins phosphorylates the retinoblastoma $(\mathrm{Rb})$ tumor suppressor protein to promote the cell cycle progression from the G1 to the $\mathrm{S}$ phase (42). However, the cell cycle can be inhibited by CDK $4 / 6$ inhibitors, thereby suppressing tumor proliferation (43). The regulation of CDK4/6 activity is associated with the ubiqui- 


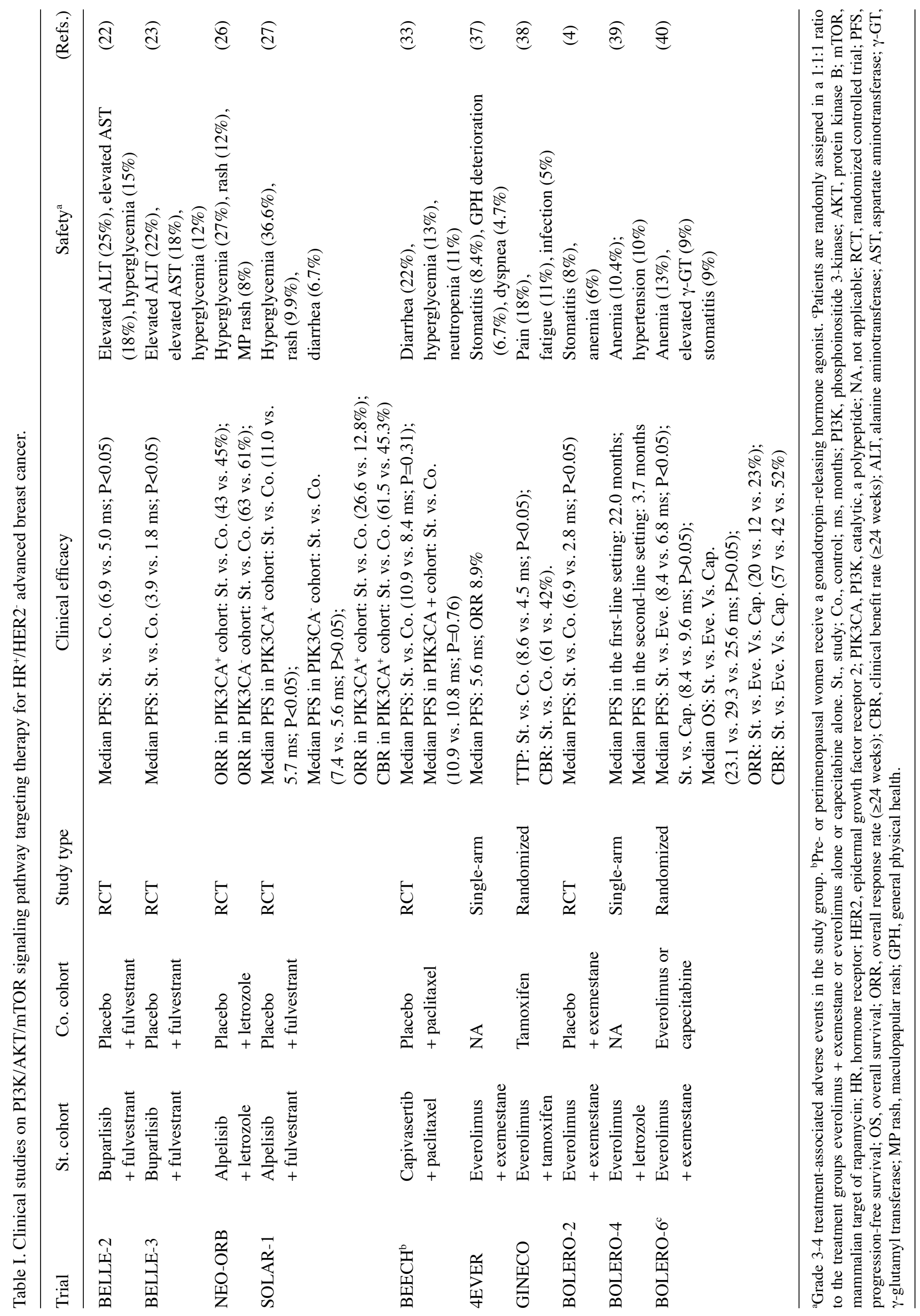




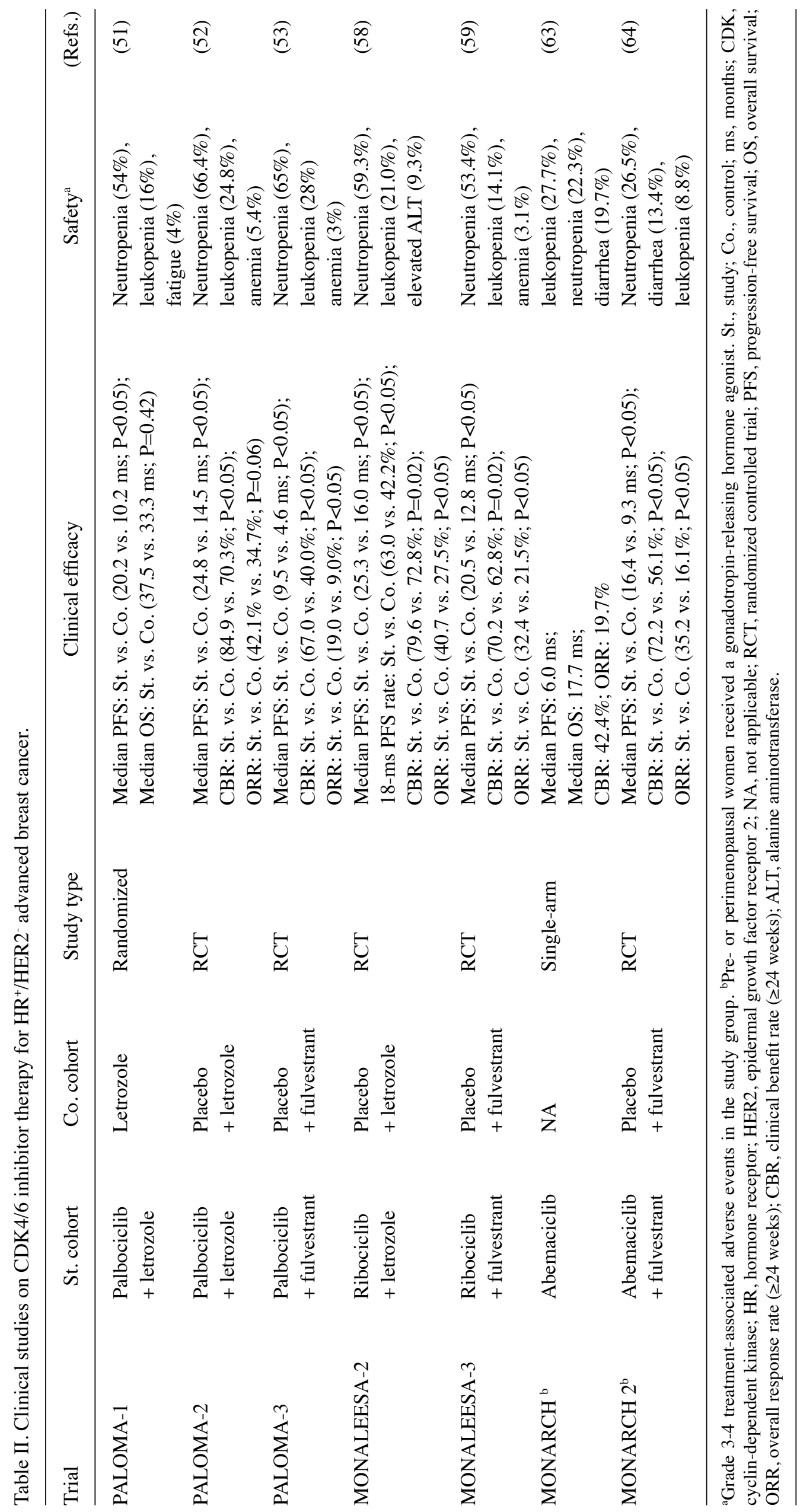




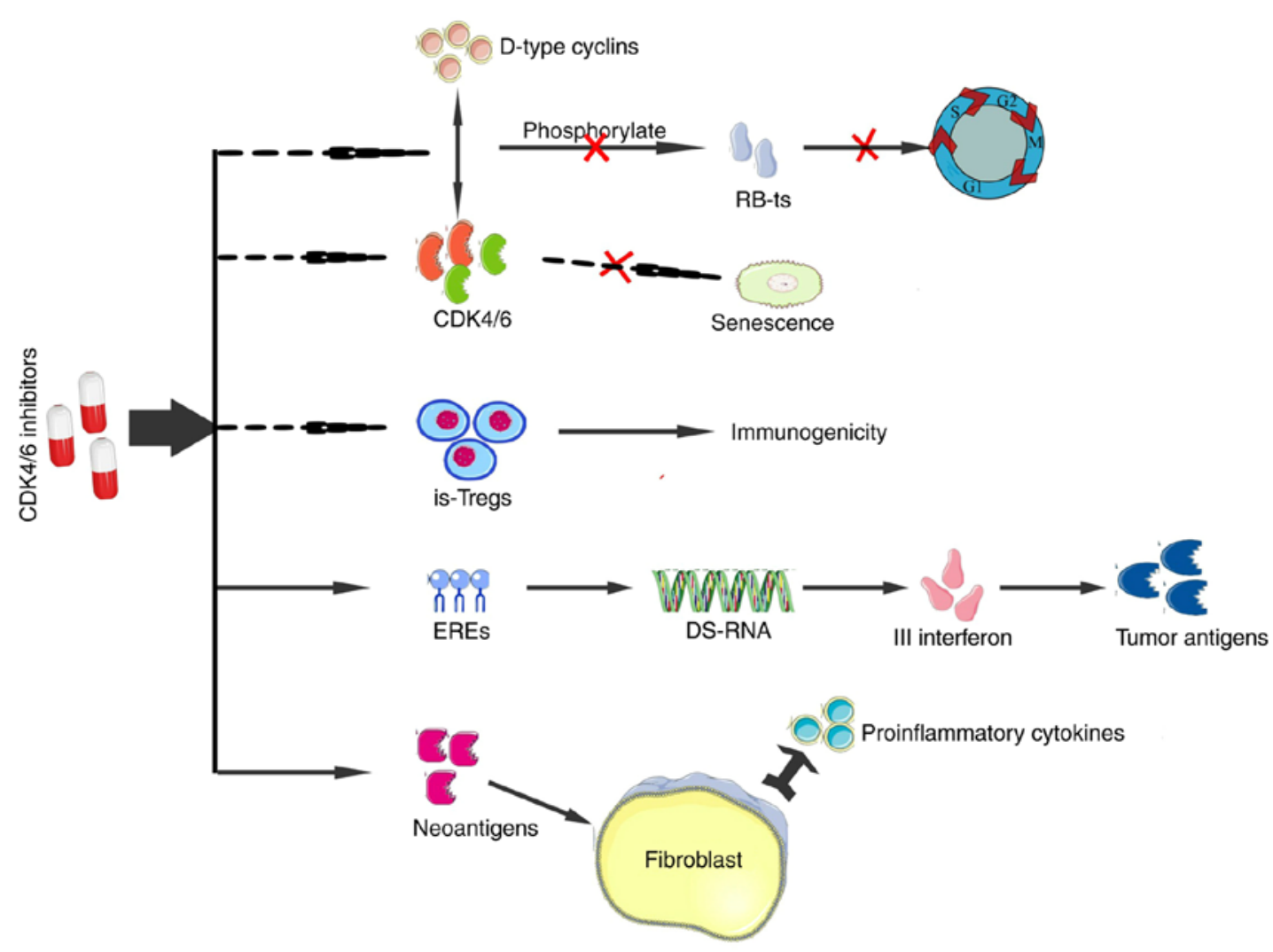

Figure 2. Mechanisms underlying the antitumor effect of PI3K/AKT/mTOR signaling pathway inhibitors. Solid arrow, promoting effect; dashed arrow, inhibiting effect; red cross solid arrow, weakening effect caused by previous step; red cross dashed arrow, enhancing effect caused by previous step. CDK4/6, cyclin-dependent kinases 4 and 6; RB-ts, retinoblastoma tumor suppressor protein; is-Tregs, immunosuppressive regulatory T cells; EREs, endogenous retrovirus elements; DS-RNA, double-stranded RNA.

tination and phosphorylation of endogenous cell inhibitors of the INK4 family (44). However, the regulation is commonly disrupted in tumors by a number of mechanisms, leading to increased CDK4/6 activity that delays senescence (45-47). CDK4/6 inhibitors can promote senescence of cancer cells by decreasing the activity of these kinases. These inhibitors exert a stronger inhibitory effect on the proliferation of immunosuppressive Tregs compared with any other type of $\mathrm{T}$ cells, thereby shifting the local immune balance over time to increase tumor immunogenicity (48). They also promote the expression of endogenous retrovirus elements, which is associated with the high level of intracellular double-stranded RNA that stimulates the production of type III interferon, ultimately bolstering the presentation of tumor antigens (48). The expression of MHC I-presented neoantigens may be activated by the CDK4/6 inhibitors, resulting in the release of proinflammatory cytokines by fibroblasts (Fig. 2) (48). Currently, three CDK4/6 inhibitors have been approved by the Food and Drug Administration in the United States for the treatment of $\mathrm{HR}^{+} / \mathrm{HER} 2{ }^{-} \mathrm{aBC}$.

Palbociclib. Palbociclib (Ibrance) is an oral, reversible, small-molecule CDK4/6 inhibitor (49). Palbociclib has been demonstrated to suppress the growth of $\mathrm{ER}^{+}$breast cancer cell lines more than that of TNBC cell lines in vitro; it also arrests the cell cycle at the G0/G1 phase and blocks the phosphorylation of $\mathrm{Rb}$ only in sensitive cell lines. In addition, it acts synergistically with tamoxifen in $\mathrm{ER}^{+}$breast cancer cell lines and even increases the sensitivity to tamoxifen in cell lines resistant to endocrine therapy (50). Based on these findings, two clinical studies, PALOMA-1 (51) and PALOMA-2 (52), were designed, and demonstrated a significantly longer median PFS and higher tumor response of $\mathrm{HR}^{+} / \mathrm{HER} 2^{-}$aBC postmenopausal patients receiving palbociclib plus letrozole compared with those receiving letrozole alone. The safety profile of the palbociclib-letrozole group was manageable; the most frequent grade 3-4 treatment-related AEs were neutropenia, leukopenia and fatigue (Table II). Similarly, the PALOMA-3 study (53) confirmed the significantly and consistently improved PFS in postmenopausal women with $\mathrm{HR}^{+} / \mathrm{HER} 2^{-}$endocrine-refractory aBC receiving palbociclib plus fulvestrant compared with fulvestrant plus placebo (Table II). Other clinical trials are currently evaluating the efficacy and safety of palbociclib in combination with fulvestrant in $\mathrm{HR}^{+} / \mathrm{HER}^{-} \mathrm{aBC}$ patients who had previously progressed on palbociclib plus aromatase inhibitor (NCT02738866) and those on palbociclib combined with aromatase inhibitor compared with chemotherapy-based treatment for $\mathrm{HR}^{+} / \mathrm{HER} 2^{-}$aBC in a Real World Setting (NCT03355157).

Ribociclib. The second small-molecule CDK4/6 inhibitor is ribociclib (LEE011), which is characterized by its oral bioavailability and high selectivity (54). A preclinical study demonstrated the antitumor efficacy of ribociclib combined with letrozole and PI3K inhibitors in $\mathrm{HR}^{+}$breast cancer in vivo (55). Based on these findings, a phase $\mathrm{Ib}$ clinical trial of ribociclib plus an endocrine agent also demonstrated clinical 


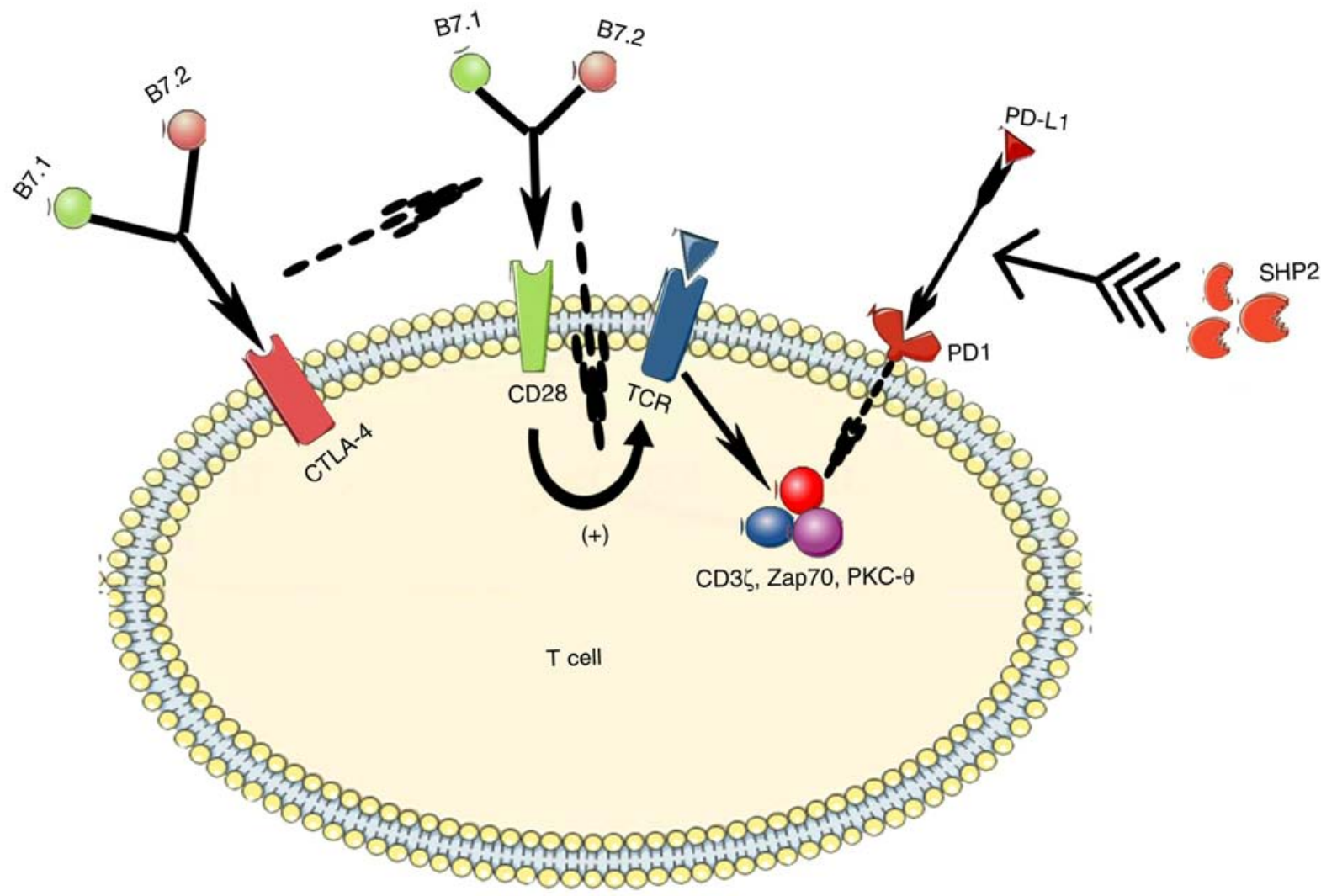

Figure 3. Mechanisms of action of PD1/PD-L1 and CTLA-4 in reducing T-cell proliferation. Solid arrow, promoting effect; dashed arrow, inhibiting effect. CTLA-4, anti-cytotoxic T lymphocyte antigen-4; TCR, T-cell receptor; PD1, programmed death 1; PD-L1, programmed death ligand-1; SHP2, Src homology 2-domain-containing tyrosine phosphatase 2 .

efficacy with acceptable toxicity in postmenopausal patients with advanced $\mathrm{HR}^{+}$breast tumor (56). This combination also significantly improved the PFS of premenopausal women with $\mathrm{HR}^{+} / \mathrm{HER} 2^{-}$aBC compared with those on placebo plus endocrine therapy (57). Two well-designed phase III RCTs, MONALEESA-2 (58) and MONALEESA-3 (59), demonstrated that ribociclib combined with hormone therapy (letrozole or fulvestrant) outperformed hormone therapy alone in postmenopausal patients with $\mathrm{HR}^{+} / \mathrm{HER} 2^{-} \mathrm{aBC}$ with regard to the median PFS, ORR and CBR. The drug toxicity in the combination cohort was tolerable, with similar grade 3-4 AEs as those of palbociclib-letrozole (Table II). Of note, the therapeutic efficacy of ribociclib was independent of PIK3CA or TP53 mutations, total Rb, Ki67 or p16 protein expression, and the CDKN2A, CCND1, or ESR1 mRNA levels (60).

Abemaciclib. Abemaciclib (LY2835219) is the third oral, small-molecule CDK4/6 inhibitor, which is structurally distinct from palbociclib and ribociclib and appears to be more selective for CDK4 compared with CDK6 (61). As a single agent, abemaciclib produced an outstanding tumor response with an acceptable safety profile in advanced $\mathrm{HR}^{+}$breast cancer (62), which warrants its further development, as monotherapy or in combination with other therapies. The MONARCH 1 phase II single-arm study (63) and the MONARCH 2 phase III RCT (64) investigated the monotherapy with abemaciclib and its combination with fulvestrant, respectively, for patients with $\mathrm{HR}^{+} / \mathrm{HER} 2$, endocrine-refractory aBC. Analysis of the results demonstrated the clinical efficacy and good tolerability of abemaciclib, both as a single agent and combined with fulvestrant. Of note, significant improvement of the median PFS, ORR and CBR was observed in the abemaciclib-fulvestrant cohort compared with fulvestrant alone. Leukopenia and neutropenia were the most common grade 3-4 AEs of abemaciclib (Table II).

\section{Anti-PD1/PD-L1}

PD1 is expressed on the surface of most T cells (65). Upon binding to its ligand PD-L1, PD1 clusters with the T-cell receptor (TCR) to form a negative costimulatory microcluster that can dephosphorylate and inactivate TCR downstream signaling molecules (CD3 $\zeta$, Zap70 and PKC- $\theta$ ) by recruiting Src homology 2-domain-containing tyrosine phosphatase 2, thereby suppressing T-cell activation and proliferation, and ultimately reducing the antitumor immune response (Fig. 3) (66-68). PD-L1 expression can markedly promote tumorigenesis and tumor invasiveness, which may be associated with the downregulation of the immune response (69).

PD1 is most frequently expressed in TNBC compared with other subsets of breast tumors (70). Previous clinical studies have mainly focused on applying anti-PD1/PD-L1 treatment to advanced TNBC, which demonstrated clinical efficacy (71-73). Recently, two phase I trials, KEYNOTE-028 (8) and JAVELIN Solid Tumor (9), documented that anti-PD1/PD-L1 monotherapy with pembrolizumab (MK-3475) or avelumab (MSB0010718C) also achieved a modest but lasting antitumor response in $\mathrm{HR}^{+} / \mathrm{HER} 2^{-} \mathrm{aBC}$ (Table III). These findings may provide a new 
Table III. Clinical studies on immunotherapy for $\mathrm{HR}^{+} / \mathrm{HER} 2^{-}$advanced breast cancer.

\begin{tabular}{|c|c|c|c|c|}
\hline Trial & Drug & Clinical efficacy & Safety ${ }^{a}$ & (Refs. \\
\hline KEYNOTE-0 $2^{\mathrm{b}}$ & Pembrolizumab & $\begin{array}{l}\text { ORR: } 12.0 \% \\
\text { CBR: } 20 \%\end{array}$ & $\begin{array}{l}\text { Autoimmune hepatitis }(4 \%) \text {, elevated } \\
\gamma \text {-GT }(4 \%), \text { muscular weakness }(4 \%) \text {, } \\
\text { nausea }(4 \%) \text {, septic shock }(4 \%)\end{array}$ & (8) \\
\hline $\mathrm{JAVELI}^{\mathrm{b}, \mathrm{c}}$ & Avelumab & ORR $2.8 \%$ & $\begin{array}{l}\text { Anemia }(1.8 \%) \text {, autoimmune hepatitis }(1.8 \%) \text {, } \\
\text { elevated } \gamma \text {-GT }(1.8 \%) \text {, fatigue }(1.8 \%)\end{array}$ & (9) \\
\hline
\end{tabular}

${ }^{\mathrm{a}}$ Grade 3-4 treatment-associated adverse events in the study group. ${ }^{\text {bPre- }}$ or perimenopausal women received a gonadotropin-releasing hormone agonist. 'The safety profile also includes triple-negative breast cancer patients. HR, hormone receptor; HER2, epidermal growth factor receptor 2; ORR, overall response rate ( $\geq 24$ weeks); CBR, clinical benefit rate ( $\geq 24$ weeks); $\gamma$-GT, $\gamma$-glutamyl transferase.

perspective for the treatment of patients with this disease; a rational recommendation is that future studies aim to evaluate the clinical efficacy and safety profile of anti-PD1/PD-L1 therapy in combination with other therapies, particularly hormone therapy, for patients with $\mathrm{HR}^{+} / \mathrm{HER} 2^{-} \mathrm{aBC}$.

\section{Anti-CTLA-4}

The CD28-B7 immunoglobulin superfamily is a critical signature in T-cell activation and tolerance, in which CD28 and CTLA-4 are two immunoregulatory molecules that competitively share their two ligands (B7.1 and B7.2) (74). CD28 is expressed in $90 \%$ of human $\mathrm{CD}^{+} \mathrm{T}$ cells and $50 \%$ of human $\mathrm{CD}^{+} \mathrm{T}$ cells, sending a costimulating signal upon TCR binding that plays a key role in the transmission of a productive immune response in many cases (75). The alteration of the number of bound TCRs is consistent with that of the CD28 presentation. However, CTLA-4 is an important negative regulator of the CD28-dependent T-cell response, with a 500- to 2,500-fold higher affinity for both B7 ligands compared with CD28 (75). As such, an increase in the CTLA-4 expression ultimately suppresses the immune response (Fig. 3). CTLA-4 blockade, in turn, increases the level of CD28 expression, which can enhance the immune response of chronic tumor-reactive $\mathrm{T}$ cells in tumors to achieve an antitumor effect (76).

Preclinical in vivo studies have indicated that inhibition of the CTLA-4 expression enhanced the endogenous immune response of immunogenic tumors, and acted synergistically with other therapies to produce an antitumor effect in less immunogenic tumors (75). Of note, anti-CTLA-4 alone is ineffective in the more poorly immunogenic tumors, as the antitumor activity of immunotherapy depends on the inherent immunogenicity of the tumor. The similarity of the ORR between anti-CTLA-4 monotherapy and its combination with chemotherapy or radiotherapy (77-79) suggests that the results of the antitumor response may only be associated with anti-CTLA-4 alone.

Tremelimumab (CP-675,206) is a fully humanized IgG2 anti-CTLA-4 monoclonal antibody that accentuates the immune activity of human T-cells by blocking the binding of CTLA-4 to B7.1 and B7.2 (80). The antitumor activity of tremelimumab as a single agent in advanced melanoma has been confirmed in numerous clinical trials (80-84), but it is inferior to that of chemotherapy (85). It appears that tremelim- umab in combination with other treatments is likely to achieve maximum clinical efficacy. A single-arm pilot study of tremelimumab plus durvalumab for the treatment of 18 patients with aBC (11 with $\mathrm{HR}^{+}$breast cancer and 7 with TNBC) demonstrated that ORR was only observed in TNBC patients (43\%), but not in $\mathrm{HR}^{+}$breast cancer patients (10). These findings mirror the results of a previous phase I clinical trial of tremelimumab combined with exemestane in 26 patients with $\mathrm{HR}^{+}$ aBC to investigate its MTD, clinical efficacy and safety (11). The best therapeutic benefit was observed in 11 patients with stable disease for $\geq 12$ weeks; however, no partial or complete response was documented. The MTD of exemestane was $6 \mathrm{mg} / \mathrm{kg}$ every 90 days. Diarrhea was the most common grade 3-4 treatment-related AE, but it was not observed in patients treated at the MTD. The treatment benefit was positively associated with the increased expression of inducible costimulator by peripheral $\mathrm{CD}^{+}$and $\mathrm{CD}^{+} \mathrm{T}$ cells that may be secondary to the immune activation following CTLA-4 blockade. These disappointing outcomes have limited the utility of tremelimumab for $\mathrm{HR}^{+} / \mathrm{HER} 2^{-}$aBC patients.

\section{Conclusions}

$\mathrm{HR}^{+} / \mathrm{HER} 2^{-} \mathrm{aBC}$ accounts for the largest proportion of advanced breast tumors. The preferred treatment to date has been endocrine therapy, which is initially effective, but eventually results in disease progression. Over the past decade, a large body of clinical studies has demonstrated the clinical activity and controllable toxicity of several molecularly targeted therapeutic agents, both as monotherapy and in combination with hormone therapy for patients with $\mathrm{HR}^{+} / \mathrm{HER} 2^{-} \mathrm{aBC}$. These agents have been approved and recommended by a number of breast cancer treatment guidelines. Due to the advent and popularity of immunotherapy, particularly with the great strides towards achieving antitumor immune response in TNBC, several clinical studies have employed immunotherapy for the treatment of patients with $\mathrm{HR}^{+} / \mathrm{HER} 2^{-} \mathrm{aBC}$ and observed some clinical benefits. Therefore, immunotherapy may become a valuable treatment modality for such patients in the future.

\section{Search strategy and inclusion criteria}

Articles published in English were searched in the PubMed and Embase databases using the search terms 'immu- 
notherapy' or 'targeted therapy' and 'breast cancer' and 'clinical trial' and 'estrogen receptor-positive'. The publications were retrieved on July 3, 2019. Clinical studies that evaluated the clinical efficacy and safety profile of targeted therapy or immunotherapy for $\mathrm{HR}^{+} / \mathrm{HER} 2^{-}$aBC met the inclusion criteria. We also retrieved relevant clinical studies currently underway in the ClinicalTrial.gov database on July 26, 2019.

\section{Acknowledgements}

Not applicable.

\section{Funding}

No funding was received.

\section{Availability of data and materials}

Not applicable.

\section{Authors' contributions}

YS: Conception and design, writing and final approval of the manuscript. LH: Writing the manuscript and figure charting. YW: Writing the manuscript and drawing the tables. QW: Writing the manuscript. WH: Writing the manuscript and drawing the tables. All authors have reviewed and approved the final version of the manuscript prior to submission.

\section{Ethics approval and consent to participate}

Not applicable.

\section{Patient consent for publication}

Not applicable.

\section{Competing interests}

The authors declare that they have no competing interests.

\section{References}

1. Parkin DM, Pisani P and Ferlay J: Global cancer statistics. CA Cancer J Clin 49: 33-64, 1, 1999.

2. Gradishar WJ, Anderson BO, Balassanian R, Blair SL, Burstein HJ, Cyr A, Elias AD, Farrar WB, Forero A, Giordano SH, et al: Invasive breast cancer version 1.2016, NCCN clinical practice guidelines in oncology. J Natl Compr Canc Netw 14: 324-354, 2016.

3. Kwa M,Li X, Novik Y, Oratz R, Jhaveri K, Wu J, Gu P, Meyers M, Muggia F, Speyer J, et al: Serial immunological parameters in a phase II trial of exemestane and low-dose oral cyclophosphamide in advanced hormone receptor-positive breast canc. Breast Cancer Res Treat 168: 57-67, 2018.

4. Baselga J, Campone M, Piccart M, Burris HA III, Rugo HS, Sahmoud T, Noguchi S, Gnant M, Pritchard KI, Lebrun F, et al: Everolimus in postmenopausal hormone-receptor-positive advanced breast cancer. N Engl J Med 366: 520-529, 2012.

5. Jiang Z, Li W, Hu X, Zhang Q, Sun T, Cui S, Wang S, Ouyang Q, Yin Y, Geng C, et al: Tucidinostat plus exemestane for postmenopausal patients with advanced, hormone receptor-positive breast cancer (ACE): A randomised, double-blind, placebo-controlled, phase 3 trial. Lancet Oncol 20: 806-815, 2019.
6. Esteva FJ, Hubbard-Lucey VM, Tang J and Pusztai L: Immunotherapy and targeted therapy combinations in metastatic breast cancer. Lancet Oncol 20: e175-e186, 2019.

7. Bianchini G, Qi Y, Alvarez RH, Iwamoto T, Coutant C, Ibrahim NK, Valero V, Cristofanilli M, Green MC, Radvanyi L, et al: Molecular anatomy of breast cancer stroma and its prognostic value in estrogen receptor-positive and -negative cancers. J Clin Oncol 28: 4316-4323, 2010.

8. Rugo HS, Delord JP, Im SA, Ott PA, Piha-Paul SA, Bedard PL, Sachdev J, Le Tourneau C, van Brummelen EMJ, Varga A, et al: Safety and antitumor activity of pembrolizumab in patients with estrogen receptor-positive/human epidermal growth factor receptor 2-negative advanced breast cancer. Clin Cancer Res 24: 2804-2811, 2018.

9. Dirix LY, Takacs I, Jerusalem G, Nikolinakos P, Arkenau HT, Forero-Torres A, Boccia R, Lippman ME, Somer R, Smakal M, et al: Avelumab, an anti-PD-L1 antibody, in patients with locally advanced or metastatic breast cancer: A phase $1 \mathrm{~b}$ JAVELIN Solid Tumor study. Breast Cancer Res Treat 167: 671-686, 2018

10. Santa-Maria CA, Kato T, Park JH, Kiyotani K, Rademaker A, Shah AN, Gross L, Blanco LZ, Jain S, Flaum L, et al: A pilot study of durvalumab and tremelimumab and immunogenomic dynamics in metastatic breast cancer. Oncotarget 9: 18985-18996, 2018.

11. Vonderheide RH, LoRusso PM, Khalil M, Gartner EM, Khaira D, Soulieres D, Dorazio P, Trosko JA, Rüter J, Mariani GL, et al: Tremelimumab in combination with exemestane in patients with advanced breast cancer and treatment-associated modulation of inducible costimulator expression on patient $\mathrm{T}$ cells. Clin Cancer Res 16: 3485-3494, 2010.

12. Lindsley CW: The Akt/PKB family of protein kinases: A review of small molecule inhibitors and progress towards target validation: A 2009 update. Curr Top Med Chem 10: 458-477, 2010.

13. Stemke-Hale K, Gonzalez-Angulo AM, Lluch A, Neve RM, Kuo WL, Davies M, Carey M, Hu Z, Guan Y, Sahin A, et al: An integrative genomic and proteomic analysis of PIK3CA, PTEN, and AKT mutations in breast cancer. Cancer Res 68: 6084-6091, 2008.

14. Huang GS, Brouwer-Visser J, Ramirez MJ, Kim CH, Hebert TM, Lin J, Arias-Pulido H, Qualls CR, Prossnitz ER, Goldberg GL, et al: Insulin-like growth factor 2 expression modulates Taxol resistance and is a candidate biomarker for reduced disease-free survival in ovarian cancer. Clin Cancer Res 16: 2999-3010, 2010.

15. Pérez-Tenorio G and Stål O; Southeast Sweden Breast Cancer Group: Activation of AKT/PKB in breast cancer predicts a worse outcome among endocrine treated patients. Br J Cancer 86: $540-545,2002$

16. Chen X, Zhao M, Hao M, Sun X, Wang J, Mao Y, Zu L, Liu J, Shen Y, Wang J and Shen K: Dual inhibition of PI3K and mTOR mitigates compensatory AKT activation and improves tamoxifen response in breast cancer. Mol Cancer Res 11: 1269-1278, 2013.

17. Mabuchi S, Ohmichi M, Kimura A, Hisamoto K, Hayakawa J, Nishio Y, Adachi K, Takahashi K, Arimoto-Ishida E, Nakatsuji Y, et al: Inhibition of phosphorylation of BAD and Raf-1 by Akt sensitizes human ovarian cancer cells to paclitaxel. J Biol Chem 277: 33490-33500, 2002.

18. Boulay A, Rudloff J, Ye J, Zumstein-Mecker S, O'Reilly T, Evans DB, Chen S and Lane HA: Dual inhibition of mTOR and estrogen receptor signaling in vitro induces cell death in models of breast cancer. Clin Cancer Res 11: 5319-5328, 2005.

19. Lui A, New J, Ogony J, Thomas S and Lewis-Wambi J: Everolimus downregulates estrogen receptor and induces autophagy in aromatase inhibitor-resistant breast cancer cells. BMC Cancer 16: 487, 2016.

20. MayerIA,Abramson VG,IsakoffSJ,Forero A,BalkoJM,KubaMG, Sanders ME, Yap JT, Van den Abbeele AD, Li Y, et al: Stand up to cancer phase Ib study of pan-phosphoinositide-3-kinase inhibitor buparlisib with letrozole in estrogen receptor-positive/human epidermal growth factor receptor 2-negative metastatic breast cancer. J Clin Oncol 32: 1202-1209, 2014.

21. Ma CX, Luo J, Naughton M, Ademuyiwa F, Suresh R, Griffith M, Griffith OL, Skidmore ZL, Spies NC, Ramu A, et al: A Phase I trial of BKM120 (Buparlisib) in combination with fulvestrant in postmenopausal women with estrogen receptor-positive metastatic breast cancer. Clin Cancer Res 22: 1583-1591, 2016.

22. Baselga J, Im SA, Iwata H, Cortés J, De Laurentiis M, Jiang Z, Arteaga CL, Jonat W, Clemons M, Ito Y, et al: Buparlisib plus fulvestrant versus placebo plus fulvestrant in postmenopausal, hormone receptor-positive, HER2-negative, advanced breast cancer (BELLE-2): A randomised, double-blind, placebo-controlled, phase 3 trial. Lancet Oncol 18: 904-916, 2017. 
23. Di Leo A, Johnston S, Lee KS, Ciruelos E, Lønning PE, Janni W, O'Regan R, Mouret-Reynier MA, Kalev D, Egle D, et al: Buparlisib plus fulvestrant in postmenopausal women with hormone-receptor-positive, HER2-negative, advanced breast cancer progressing on or after mTOR inhibition (BELLE-3) A randomised, double-blind, placebo-controlled, phase 3 trial. Lancet Oncol 19: 87-100, 2018.

24. Mayer IA, Abramson VG, Formisano L, Balko JM, Estrada MV, Sanders ME, Juric D, Solit D, Berger MF, Won HH, et al: A phase Ib study of alpelisib (BYL719), a PI3K $\alpha$-specific inhibitor, with letrozole in ER+/HER2-metastatic breast cancer. Clin Cancer Res 23: 26-34, 2017.

25. Juric D, Janku F, Rodón J, Burris HA, Mayer IA, Schuler M, Seggewiss-Bernhardt R, Gil-Martin M, Middleton MR, Baselga J, et al: Alpelisib plus fulvestrant in PIK3CA-Altered and PIK3CA-wild-type estrogen receptor-positive advanced breast cancer: A phase $1 \mathrm{~b}$ clinical trial. JAMA Oncol 5: e184475, 2019.

26. Mayer IA, Prat A, Egle D, Blau S, Fidalgo JAP, Gnant M, Fasching PA, Colleoni M, Wolff AC, Winer EP, et al: A phase II randomized study of neoadjuvant letrozole plus alpelisib for hormone receptor-positive, human epidermal growth factor receptor 2-negative breast cancer (NEO-ORB). Clin Cancer Res 25: 2975-2987, 2019.

27. André F, Ciruelos E, Rubovszky G, Campone M, Loibl S, Rugo HS, Iwata H, Conte P, Mayer IA, Kaufman B, et al: Alpelisib for PIK3CA-mutated, hormone receptor-positive advanced breast cancer. N Engl J Med 380: 1929-1940, 2019.

28. Li Y: MK-2206: A potent oral allosteric AKT inhibitor. Cancer Res 69: DDT01-1, 2009

29. Ma CX, Sanchez C, Gao F, Crowder R, Naughton M, Pluard T, Creekmore A, Guo Z, Hoog J, Lockhart AC, et al: A phase I study of the AKT inhibitor MK-2206 in combination with hormonal therapy in postmenopausal women with estrogen receptor-positive metastatic breast cancer. Clin Cancer Res 22 2650-2658, 2016

30. Xing Y, Lin NU, Maurer MA, Chen H, Mahvash A, Sahin A, Akcakanat A, Li Y, Abramson V, Litton J, et al: Phase II trial of AKT inhibitor MK-2206 in patients with advanced breast cancer who have tumors with PIK3CA or AKT mutations, and/or PTEN loss/PTEN mutation. Breast Cancer Res 21: 78, 2019.

31. Ma CX, Suman V, Goetz MP, Northfelt D, Burkard ME, Ademuyiwa F, Naughton M, Margenthaler J, Aft R, Gray R, et al: A phase II trial of neoadjuvant MK-2206, an AKT inhibitor, with anastrozole in clinical stage II or III PIK3CA-mutant ER-positive and HER2-negative breast cancer. Clin Cancer Res 23: 6823-6832, 2017.

32. Banerji U, Dean EJ, Pérez-Fidalgo JA, Batist G, Bedard PL, You B, Westin SN, Kabos P, Garrett MD, Tall M, et al: A Phase I open-label study to identify a dosing regimen of the Pan-AKT inhibitor AZD5363 for evaluation in solid tumors and in PIK3CA-mutated breast and gynecologic cancers. Clin Cancer Res 24: 2050-2059, 2018.

33. Turner NC, Alarcón E, Armstrong AC, Philco M, López Chuken YA, Sablin MP, Tamura K, Gómez Villanueva A, Pérez-Fidalgo JA, Cheung SYA, et al: BEECH: A dose-finding run-in followed by a randomised phase II study assessing the efficacy of AKT inhibitor capivasertib (AZD5363) combined with paclitaxel in patients with estrogen receptor-positive advanced or metastatic breast cancer, and in a PIK3CA mutant sub-population. Ann Oncol 30: 774-780, 2019.

34. Ribas R, Pancholi S, Guest SK, Marangoni E, Gao Q, Thuleau A, Simigdala N, Polanska UM, Campbell H, Rani A, et al: AKT antagonist AZD5363 influences estrogen receptor function in endocrine-resistant breast cancer and synergizes with fulvestrant (ICI182780) in vivo. Mol Cancer Ther 14: 2035-2048, 2015

35. Efeyan A and Sabatini DM: mTOR and cancer: Many loops in one pathway. Curr Opin Cell Biol 22: 169-176, 2010.

36. Baselga J, Semiglazov V, van Dam P, Manikhas A, Bellet M, Mayordomo J, Campone M, Kubista E, Greil R, Bianchi G, et al: Phase II randomized study of neoadjuvant everolimus plus letrozole compared with placebo plus letrozole in patients with estrogen receptor-positive breast cancer. J Clin Oncol 27: 2630-2637, 2009.

37. Tesch H, Stoetzer O, Decker T, Kurbacher CM, Marmé F, Schneeweiss A, Mundhenke C, Distelrath A, Fasching PA, Lux MP, et al: Efficacy and safety of everolimus plus exemestane in postmenopausal women with hormone receptor-positive, human epidermal growth factor receptor 2-negative locally advanced or metastatic breast cancer: Results of the single-arm, phase IIIB 4EVER trial. Int J Cancer 144: 877-885, 2019.
38. Bachelot T, Bourgier C, Cropet C, Ray-Coquard I, Ferrero JM, Freyer G, Abadie-Lacourtoisie S, Eymard JC, Debled M, Spaëth D, et al: Randomized phase II trial of everolimus in combination with tamoxifen in patients with hormone receptor-positive, human epidermal growth factor receptor 2-negative metastatic breast cancer with prior exposure to aromatase inhibitors: A GINECO study. J Clin Oncol 30: 2718-2724, 2012.

39. Royce M, Bachelot T, Villanueva C, Özgüroglu M, Azevedo SJ, Cruz FM, Debled M, Hegg R, Toyama T, Falkson C, et al: Everolimus plus endocrine therapy for postmenopausal women with estrogen receptor-positive, human epidermal growth factor receptor 2-negative advanced breast cancer: A clinical trial. JAMA Oncol 4: 977-984, 2018.

40. Jerusalem G, de Boer RH, Hurvitz S, Yardley DA, Kovalenko E, Ejlertsen B, Blau S, Özgüroglu M, Landherr L, Ewertz M, et al: Everolimus plus exemestane vs everolimus or capecitabine monotherapy for estrogen receptor-positive, HER2-negative advanced breast cancer: The BOLERO-6 randomized clinical trial. JAMA Oncol 4: 1367-1374, 2018.

41. Generali D, Venturini S, Rognoni C, Ciani O, Pusztai L, Loi S, Jerusalem G, Bottini A and Tarricone R: A network meta-analysis of everolimus plus exemestane versus chemotherapy in the first- and second-line treatment of estrogen receptor-positive metastatic breast cancer. Breast Cancer Res Treat 152: 95-117, 2015.

42. Weinberg RA: The retinoblastoma protein and cell cycle control. Cell 81: 323-330, 1995.

43. Sherr CJ and Roberts JM: CDK inhibitors: Positive and negative regulators of G1-phase progression. Genes Dev 13: 1501-1512, 1999.

44. Carnero A and Hannon GJ: The INK4 family of CDK inhibitors. Curr Top Microbiol Immunol 227: 43-55, 1998.

45. Hall $M$ and Peters G: Genetic alterations of cyclins, cyclin-dependent kinases, and Cdk inhibitors in human cancer. Adv Cancer Res 68: 67-108, 1996.

46. Sherr CJ: Cancer cell cycles. Science 274: 1672-1677, 1996.

47. Shapiro GI: Cyclin-dependent kinase pathways as targets for cancer treatment. J Clin Oncol 24: 1770-1783, 2006.

48. Bates GJ, Fox SB, Han C, Leek RD, Garcia JF, Harris AL and Banham AH: Quantification of regulatory T cells enables the identification of high-risk breast cancer patients and those at risk of late relapse. J Clin Oncol 24: 5373-5380, 2006.

49. Fry DW, Harvey PJ, Keller PR, Elliott WL, Meade M, Trachet E, Albassam M, Zheng X, Leopold WR, Pryer NK and Toogood PL: Specific inhibition of cyclin-dependent kinase 4/6 by PD 0332991 and associated antitumor activity in human tumor xenografts. Mol Cancer Ther 3: 1427-1438, 2004.

50. Finn RS, Dering J, Conklin D, Kalous O, Cohen DJ, Desai AJ, Ginther C, Atefi M, Chen I, Fowst C, et al: PD 0332991, a selective cyclin D kinase $4 / 6$ inhibitor, preferentially inhibits proliferation of luminal estrogen receptor-positive human breast cancer cell lines in vitro. Breast Cancer Res 11: R77, 2009.

51. Finn RS, Crown JP, Lang I, Boer K, Bondarenko IM, Kulyk SO, Ettl J, Patel R, Pinter T, Schmidt M, et al: The cyclin-dependent kinase 4/6 inhibitor palbociclib in combination with letrozole versus letrozole alone as first-line treatment of oestrogen receptor-positive, HER2-negative, advanced breast cancer (PALOMA-1/TRIO-18): A randomised phase 2 study. Lancet Oncol 16: 25-35, 2015

52. Finn RS, Martin M, Rugo HS, Jones S, Im SA, Gelmon K, Harbeck N, Lipatov ON, Walshe JM, Moulder S, et al: Palbociclib and letrozole in advanced breast cancer. N Engl J Med 375: 1925-1936, 2016

53. Cristofanilli M, Turner NC, Bondarenko I, Ro J, Im SA, Masuda N, Colleoni M, DeMichele A, Loi S, Verma S, et al: Fulvestrant plus palbociclib versus fulvestrant plus placebo for treatment of hormone-receptor-positive, HER2-negative metastatic breast cancer that progressed on previous endocrine therapy (PALOMA-3): Final analysis of the multicentre, double-blind, phase 3 randomised controlled trial. Lancet Oncol 17: 425-439, 2016.

54. Kim S, Loo A, Chopra R, Caponigro G, Huang A, Vora S, Parasuraman S, Howard S, Keen N, Sellers W and Brain C. LEE011: An orally bioavailable, selective small molecule inhibitor of CDK4/6-Reactivating Rb in cancer. Mol Cancer Ther 12 (11 Suppl): PR02, 2013.

55. O'Brien NA, Tomaso ED, Ayala R, Tong L, Issakhanian S, Linnartz R, Finn RS, Hirawat S and Slamon DJ: In vivo efficacy of combined targeting of CDK4/6, ER and PI3K signaling in ER+breast cancer. Cancer Res 74: (19 Suppl): S4756, 2014. 
56. Juric D, Munster PN, Campone M, Ismail-Khan R García-Estevez L, Hamilton EP, Becerra C, De Boer RH, Hui R and Goncalves A: Ribociclib (LEE011) and letrozole in estrogen receptor-positive (ER+), HER2-negative (HER2-) advanced breast cancer $(\mathrm{aBC})$ : Phase Ib safety, preliminary efficacy and molecular analysis. J Clin Oncol 34 (15 Suppl): S568, 2016.

57. Tripathy D Sohn J, Im SA, Colleoni M, Franke F, Bardia A, Harbeck N, Hurvitz S, Chow L, Lee KS, et al: First-line ribociclib vs. placebo with goserelin and tamoxifen or a non-steroidal aromatase inhibitor in premenopausal women with hormone receptor-positive, HER2- negative advanced breast cancer: Results from the randomized phase III MONALEESA-7 trial. Cancer Res 78 (4 Suppl): GS2-05, 2018.

58. Hortobagyi GN, Stemmer SM, Burris HA, Yap YS, Sonke GS, Paluch-Shimon S, Campone M, Blackwell KL, André F, Winer EP, et al: Ribociclib as first-line therapy for HR-positive, advanced breast cancer. N Engl J Med 375: 1738-1748, 2016.

59. Slamon DJ, Neven P, Chia S, Fasching PA, De Laurentiis M, Im SA, Petrakova K, Bianchi GV, Esteva FJ, Martín M, et al: Phase III randomized study of ribociclib and fulvestrant in hormone receptor-positive, human epidermal growth factor receptor 2-negative advanced breast cancer: MONALEESA-3. J Clin Oncol 36: 2465-2472, 2018.

60. Hortobagyi GN, Stemmer SM, Burris HA, Yap YS, Sonke GS, Paluch-Shimon S, Campone M, Petrakova K, Blackwell KL, Winer EP, et al: Updated results from MONALEESA-2, a phase III trial of first-line ribociclib plus letrozole versus placebo plus letrozole in hormone receptor-positive, HER2-negative advanced breast cancer. Ann Oncol 29: 1541-1547, 2018.

61. Gelbert LM, Cai S, Lin X, Sanchez-Martinez C, Del Prado M, Lallena MJ, Torres R, Ajamie RT, Wishart GN, Flack RS, et al: Preclinical characterization of the CDK4/6 inhibitor LY2835219: In-vivo cell cycle-dependent/independent anti-tumor activities alone/in combination with gemcitabine. Invest New Drugs 32: 825-837, 2014

62. Patnaik A, Rosen LS, Tolaney SM, Tolcher AW, Goldman JW, Gandhi L, Papadopoulos KP, Beeram M, Rasco DW, Hilton JF, et al: Efficacy and safety of abemaciclib, an inhibitor of CDK4 and CDK6, for patients with breast cancer, non-small cell lung cancer, and other solid tumors. Cancer Discov 6: 740-753, 2016.

63. Dickler MN, Tolaney SM, Rugo HS, Cortés J, Diéras V, Patt D, Wildiers H,Hudis CA,O'Shaughnessy J,ZamoraE, et al:MONARCH 1 , a phase II study of abemaciclib, a CDK4 and CDK6 inhibitor, as a single agent, in patients with refractory $\mathrm{HR}^{+} / \mathrm{HER} 2$ metastatic breast cancer. Clin Cancer Res 23: 5218-5224, 2017.

64. Sledge GW Jr, Toi M, Neven P, Sohn J, Inoue K, Pivot X, Burdaeva O, Okera M, Masuda N, Kaufman PA, et al: MONARCH 2: Abemaciclib in combination with fulvestrant in women with HR+/HER2-advanced breast cancer who had progressed while receiving endocrine therapy. J Clin Oncol 35: 2875-2884, 2017.

65. Iwai Y, Okazaki T, Nishimura H, Kawasaki A, Yagita H and Honjo T: Microanatomical localization of PD-1 in human tonsils. Immunol Lett 83: 215-220, 2002.

66. Okazaki T, Maeda A, Nishimura H, Kurosaki T and Honjo T: PD-1 immunoreceptor inhibits B cell receptor-mediated signaling by recruiting src homology 2-domain-containing tyrosine phosphatase 2 to phosphotyrosine. Proc Natl Acad Sci USA 98: 13866-13871, 2001.

67. Yokosuka T, Takamatsu M, Kobayashi-Imanishi W Hashimoto-Tane A, Azuma M and Saito T: Programmed cell death 1 forms negative costimulatory microclusters that directly inhibit T cell receptor signaling by recruiting phosphatase SHP2. J Exp Med 209: 1201-1217, 2012.

68. Sheppard KA, Fitz LJ,Lee JM,Benander C, George JA, Wooters J, Qiu Y, Jussif JM, Carter LL, Wood CR and Chaudhary D: PD-1 inhibits T-cell receptor induced phosphorylation of the ZAP70/CD3zeta signalosome and downstream signaling to PKCtheta. Febs Lett 574: 37-41, 2004

69. Iwai $\mathrm{Y}$, Ishida M, Tanaka $\mathrm{Y}$, Okazaki $\mathrm{T}$, Honjo $\mathrm{T}$ and Minato $\mathrm{N}$ : Involvement of PD-L1 on tumor cells in the escape from host immune system and tumor immunotherapy by PD-L1 blockade. Proc Natl Acad Sci USA 99: 12293-12297, 2002.
70. Ali HR, Glont SE, Blows FM, Provenzano E, Dawson SJ, Liu B, Hiller L, Dunn J, Poole CJ, Bowden S, et al: PD-L1 protein expression in breast cancer is rare, enriched in basal-like tumours and associated with infiltrating lymphocytes. Ann Oncol y 26: 1488-1493, 2015.

71. Nanda R, Chow LQ, Dees EC, Berger R, Gupta S, Geva R, Pusztai L, Pathiraja K, Aktan G, Cheng JD, et al: Pembrolizumab in patients with advanced triple-negative breast cancer: Phase $\mathrm{Ib}$ KEYNOTE-012 study. J Clin Oncol 34: 2460-2467, 2016.

72. Adams S, Schmid P, Rugo HS, Winer EP, Loirat D, Awada A, Cescon DW, Iwata H, Campone M, Nanda R, et al: Pembrolizumab monotherapy for previously treated metastatic triple-negative breast cancer: Cohort A of the phase II KEYNOTE-086 study. Ann Oncol 30: 397-404, 2019.

73. Adams S, Loi S, Toppmeyer D, Cescon DW, De Laurentiis M, Nanda R, Winer EP, Mukai H, Tamura K, Armstrong A, et al: Pembrolizumab monotherapy for previously untreated, PD-L1-positive, metastatic triple-negative breast cancer: Cohort $\mathrm{B}$ of the phase II KEYNOTE-086 study. Ann Oncol 30: 405-411, 2019.

74. Greenwald RJ, Freeman GJ and Sharpe AH: The B7 family revisited. Annu Rev Immunol 23: 515-548, 2005.

75. Peggs KS, Quezada SA, Korman AJ and Allison JP: Principles and use of anti-CTLA4 antibody in human cancer immunotherapy. Curr Opin Immunol 18: 206-213, 2006.

76. Egen JG, Kuhns MS and Allison JP: CTLA-4: New insights into its biological function and use in tumor immunotherapy. Nat Immunol 3: 611-618, 2002.

77. Demaria S, Kawashima N, Yang AM, Devitt ML, Babb JS, Allison JP and Formenti SC: Immune-mediated inhibition of metastases after treatment with local radiation and CTLA-4 blockade in a mouse model of breast cancer. Clin Cancer Res 11: 728-734, 2005

78. Mokyr MB, Kalinichenko T, Gorelik L and Bluestone JA: Realization of the therapeutic potential of CTLA-4 blockade in low-dose chemotherapy-treated tumor-bearing mice. Cancer Res 58: 5301-5304, 1998.

79. Attia P, Phan GQ, Maker AV, Robinson MR, Quezado MM, Yang JC, Sherry RM, Topalian SL, Kammula US, Royal RE, et al: Autoimmunity correlates with tumor regression in patients with metastatic melanoma treated with anti-cytotoxic T-lymphocyte antigen-4. J Clin Oncol 23: 6043-6053, 2005.

80. Tarhini AA and Kirkwood JM: Tremelimumab (CP-675,206): a fully human anticytotoxic $\mathrm{T}$ lymphocyte-associated antigen 4 monoclonal antibody for treatment of patients with advanced cancers. Expert Opin Biol Ther 8: 1583-1593, 2008.

81. Ribas A: Overcoming immunologic tolerance to melanoma: Targeting CTLA-4 with tremelimumab (CP-675,206). Oncologist 13 (Suppl 4): S10-S15, 2008.

82. Ribas A, Camacho LH, Lopez-Berestein G, Pavlov D, Bulanhagui CA, Millham R, Comin-Anduix B, Reuben JM, Seja E, Parker CA, et al: Antitumor activity in melanoma and anti-self responses in a phase I trial with the anti-cytotoxic $\mathrm{T}$ lymphocyte-associated antigen 4 monoclonal antibody CP-675,206. J Clin Oncol 23: 8968-8977, 2005.

83. Ribas A, Comin-Anduix B, Economou JS, Donahue TR, de la Rocha P, Morris LF, Jalil J, Dissette VB, Shintaku IP, Glaspy JA, et al: Intratumoral immune cell infiltrates, FoxP3, and indoleamine 2,3-dioxygenase in patients with melanoma undergoing CTLA4 blockade. Clin Cancer Res 15: 390-399, 2009.

84. Camacho LH, Antonia S, Sosman J, Kirkwood JM, Gajewski TF, Redman B, Pavlov D, Bulanhagui C, Bozon VA, Gomez-Navarro J and bRibas A: Phase I/II trial of tremelimumab in patients with metastatic melanoma. J Clin Oncol 27: 1075-1081, 2009.

85. Ribas A, Hauschild A, Kefford R,Punt CJ,Haanen JB, Marmol M, Garbe C, Gomez-Navarro J, Pavlov D and Marshall M: Phase III, open-label, randomized, comparative study of tremelimumab (CP-675,206) and chemotherapy [temozolomide (TMZ) or dacarbazine (DTIC)] in patients with advanced melanoma. J Clin Oncol 26 (15 Suppl): LBA9011, 2008. 